\title{
The surgeon's role in optimizing medical therapy and maintaining compliance with secondary prevention guidelines in patients undergoing coronary artery bypass grafting
}

\author{
Harold L. Lazar, MD
}

Despite receiving complete revascularization using multiple arterial conduits, patients who undergo coronary artery bypass grafting (CABG) are still susceptible to recurrent major adverse cardiovascular events (MACE) owing to the progression of atherosclerotic disease in saphenous vein grafts (SVGs) and native, ungrafted coronary vessels. This is more likely to occur in patients who are obese, have diabetes, have hyperlipidemia, have hypertension, have chronic kidney disease, or who are smokers. Unless these risk factors are properly controlled, the long-term benefits of CABG will be jeopardized. Unfortunately, guideline-directed medical therapy (GDMT) to achieve secondary prevention is underused in CABG patients, ${ }^{1,2}$ and GDMT use has been shown to be significantly lower than in patients who have undergone a percutaneous coronary intervention (PCI). ${ }^{3}$ As a result, the superior outcomes achieved with CABG compared with PCI early after revascularization might not be apparent in the long term, given the lower compliance with GDMT in CABG patients compared with PCI patients. ${ }^{3,4}$

The aims of this Invited Commentary are to (1) review the current GDMT for CABG patients, (2) review the current level of compliance with these guidelines, (3) determine the factors responsible for the poor compliance with GDMT, and (4) develop interventions and strategies that can be instituted by surgeons to ensure that $\mathrm{CABG}$ patients continue to receive GDMT to achieve the most optimal long-term outcomes following surgical revascularization.

\section{CURRENT RECOMMENDATIONS FOR OPTIMAL MEDICAL THERAPY IN CABG PATIENTS \\ Antiplatelet Therapy}

Aspirin (ASA) therapy following CABG has been shown to improve SVG patency, decrease mortality, and reduce the incidence of myocardial infarction (MI), stroke, and renal failure. ${ }^{5-7}$ The ideal time for initiating ASA appears to be

\footnotetext{
From the Boston University School of Medicine, Boston, Mass.

Received for publication Sept 10, 2019; revisions received Sept 26, 2019; accepted for publication Sept 28, 2019; available ahead of print Dec 13, 2019.

Address for reprints: Harold L. Lazar, MD, Boston University School of Medicine, Boston, MA 02118 (E-mail: harold.1.lazar@gmail.com).

J Thorac Cardiovasc Surg 2020;160:691-8 0022-5223/\$36.00

Copyright (C) 2019 Published by Elsevier Inc. on behalf of The American Association for Thoracic Surgery

https://doi.org/10.1016/j.jtcvs.2019.09.195
}

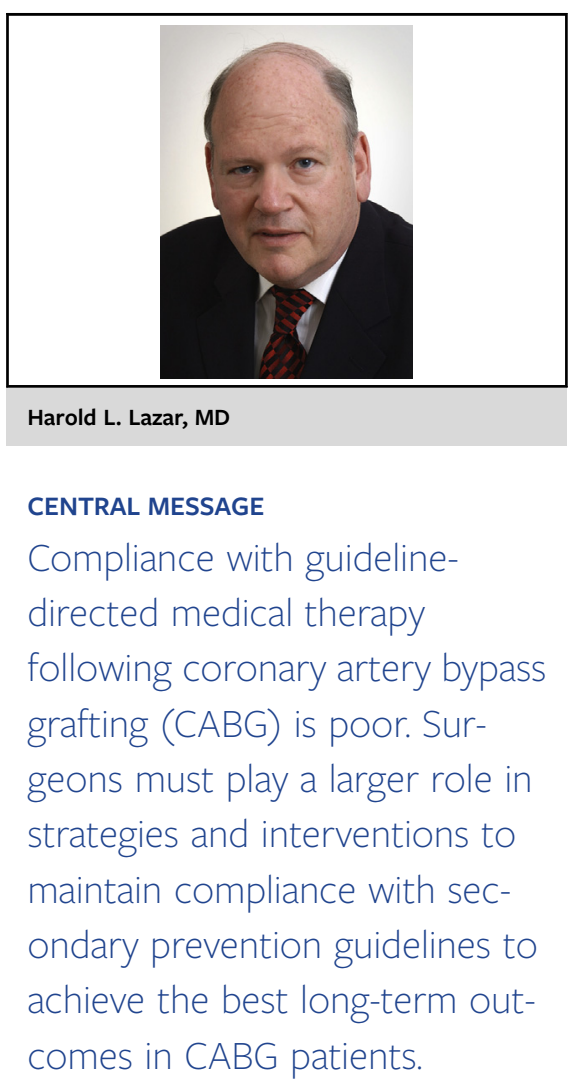

See Commentary on page 699. 
grafted and ungrafted vessels. ${ }^{13}$ Therefore, all CABG patients, irrespective of the type of conduit used, will benefit from ASA therapy.

Dual-antiplatelet therapy (DAPT) combining ASA with a $\mathrm{P} 2 \mathrm{Y} 12$ inhibitor (clopidogrel, prasurgel, or tricagrelor) is recommended only for $\mathrm{CABG}$ patients who have previously undergone PCI stent implantation, and in those CABG patients in whom DAPT has already been instituted for ACS. There is currently insufficient evidence to recommend DAPT in stable CABG patients who have not previously undergone a PCI with a stent. Ticagrelor and prasurgel exert more potent and consistent platelet inhibition and have a faster onset and offset of action than clopidogrel. In patients with ACS treated with ticagrelor, prasurgel, or clopidogrel who must now undergo $\mathrm{CABG}$, to reduce the risk of bleeding complications, elective CABG should be postponed for at least 3 days after discontinuation of ticagrelor, 5 days after clopidogrel, and 7 days after parasurgel. ${ }^{14}$

The current recommendations for antiplatelet therapy in the $\mathrm{CABG}$ patient are as follows:

- ASA should be administered preoperatively and within 6 hours after CABG in doses of $81 \mathrm{mg}$ to $325 \mathrm{mg}$ and should be continued indefinitely to reduce the incidence of graft occlusion and MACE; class I, level of evidence (LOE) A. ${ }^{14}$

- Following off-pump CABG, DAPT should be administered for 1 year with ASA (81 mg once daily) and clopidogrel (75 mg once daily) to reduce graft occlusion; class I, LOE A. ${ }^{14}$

- In patients who receive DAPT for PCI stent implantation and then undergo CABG, DAPT should be resumed postoperative and continued for the recommended duration for stent implantation; class I, LOE C. ${ }^{14}$

- In patients with ACS being treated with DAPT who must now undergo CABG, DAPT should be resumed after CABG to complete 12 months of DAPT therapy after ACS; class I, LOE C. ${ }^{14}$

\section{Angiotensin-Converting Enzyme (ACE) Inhibitors and Management of Hypertensive CABG Patients}

Hypertension is a major modifiable risk factor for limiting the development and progression of atherosclerosis and has been shown to increase long-term mortality in CABG patients. ${ }^{15}$ To date, no trials have been undertaken to determine the ideal target for blood pressure control in CABG patients. Nevertheless, it is reasonable to target a systolic blood pressure of $<140 \mathrm{~mm} \mathrm{Hg}$ in CABG patients. ${ }^{14}$ In view of their vasculoprotective and antihypertensive properties, ACE inhibitors should be included in all antihypertensive management therapies for CABG patients. The beneficial effects of ACE inhibitors derive not only from their ability to lower blood pressure, but also from their vasculoprotective and antiatherogenic properties, which include minimizing thrombosis by reducing platelet aggregation ${ }^{16}$ and limiting vascular inflammation and oxidative stress by enhancing nitric oxide production. ${ }^{17}$ In clinical trials involving patients undergoing CABG surgery, ACE inhibitors significantly reduced the long-term composite endpoints of cardiac death, acute MI, and congestive heart failure. ${ }^{18,19}$ The beneficial effects of ACE inhibitors were seen in multiple populations: men and women, all age groups, and individuals with or without hypertension, diabetes, hyperlipidemia, and cerebrovascular disease. Diabetic $\mathrm{CABG}$ patients receiving ACE inhibitors have shown significantly reduced perioperative mortality and improved 3 -year event-free survival. ${ }^{20,21}$ Therefore, ACE inhibitor therapy will benefit all CABG patients regardless of whether or not they have a diagnosis of hypertension.

Patients who receive ACE inhibitors before undergoing CABG may develop hypotension due to decreased systemic vascular resistance, especially while on cardiopulmonary bypass. $^{22}$ Withholding ACE inhibitors in elective CABG patients for 24 to 48 hours before surgery attenuates their vasodilatory effects and reduces the need for vasopressor agents. ${ }^{17,23}$ Hypotension after initiation of ACE inhibitors in postoperative CABG patients is usually related to the dosage used, the levels of hydration and intravascular volume, and the presence of underlying renovascular disease. In the postoperative period, ACE inhibitors should be initiated only after beta-blockers have been instituted for 24 to 48 hours and systolic blood pressure remains $>100 \mathrm{~mm} \mathrm{Hg}$.

Current guidelines for the use of ACE inhibitors in CABG patients are as follows:

- ACE inhibitors or angiotensin receptor blockers (ARBs) in a patient intolerant of ACE inhibitors initiated before CABG should be instituted postoperatively once the patient is stable, unless contraindicated; class I, LOE B. ${ }^{14}$

- ACE inhibitions or ARBs should be initiated postoperatively and continued indefinitely in CABG patients who were not receiving them preoperatively and who are stable, have an ejection fraction $<40 \%$, and who have hypertension, diabetes, or chronic kidney disease, unless otherwise contraindicated; class I, LOE A. ${ }^{14}$

- It is reasonable to initiate ACE inhibitors or ARBs postoperatively and to continue them indefinitely in all CABG patients who were not receiving them preoperatively and are considered at low risk (ie, patients with a normal ejection fraction and in whom cardiovascular factors are well controlled), unless otherwise contraindicated; class IIA, LOE B. ${ }^{14,24}$

\section{Antilipid Therapy}

Statins. Statins have been shown to reduce the incidence of SVG stenosis and occlusion, cardiovascular-related death, stroke, recurrent angina, ACS, and the need for repeat revascularization procedures in $\mathrm{CABG}$ patients with or without 
elevated lipid profiles. These beneficial effects are due to their "pleiotropic" properties, which include improved endothelial and vasomotor function and decreased oxidative stress, vascular inflammation, and platelet aggregation. ${ }^{25-27}$ There is no evidence to support the use of one statin over another. High-intensity statin therapy to achieve a low-density lipoprotein (LDL) level $<100 \mathrm{mg} / \mathrm{dL}$ provide increased protection from long-term MACE. ${ }^{28,29}$

The current guidelines for statin therapy in the CABG patients are as follows:

- All patients undergoing CABG should receive statin therapy, unless contraindicated, before surgery and reinstituted early after surgery when the patients can tolerate oral medication and continued indefinitely; class I, LOE A. ${ }^{14,24}$

- In CABG patients, high-dose statin therapy (40-80 mg) should be used to achieve at least a 30\% drop LDL level in patients age $<75$ years; class I, LOE A. ${ }^{14,24}$

- Moderate-intensity statin therapy should be administered to CABG patients who are intolerant of high-intensity therapy and patients at increased risk of drug interactions (age $>75$ years); class I, LOE A. ${ }^{14,24}$

- Statin therapy should not be discontinued before or after CABG unless the patient is having an adverse reaction to therapy; class III, LOE B. ${ }^{14,24}$

\section{High-Density Lipoprotein Management}

CABG patients may still be at risk for cardiovascular MACE even with a lowered LDL level. Low high-density lipoprotein (HDL) levels have been linked to worse longterm survival and a higher risk of MACE following CABG. ${ }^{30}$

The Lopid Coronary Angiography Trial (LOCAT), the only HDL trial involving CABG patients reported to date, randomized patients to receive either slow-release gemfibrozil $\left(1200 \mathrm{mg} /\right.$ day) or placebo. ${ }^{31}$ Gemfibrozil increased HDL levels, decreased the progression of native coronary artery disease, and decreased the incidence of new lesions in SVGs $(2 \%$ vs $14 \% ; P<.001)$. However, this trial was performed in an era before the routine use of statins following CABG surgery. In addition, gemfibrozil carries increased side effects, especially when combined with statins, which include muscle pain and rhabdomyolysis. ${ }^{32}$ Therefore, these agents have not been advocated for increasing HDL levels in CABG patients already receiving statins.

\section{Triglyceride Management}

High triglyceride level is linked to an increased risk of coronary artery disease and has been associated with worse outcomes following $\mathrm{CABG}$, including increased risk for a repeat coronary revascularization procedure, ${ }^{33,34}$ MACE and death, ${ }^{35}$ and SVG occlusion. ${ }^{36}$ Although statins may have some benefit in decreasing triglyceride levels, the first-line therapy for hypertriglyceridemia involves diet modification, exercise, weight loss, carbohydrate restriction, and reduced alcohol intake. Although no prospective trials have shown any benefit of adding other medications to treat hypertriglyceridemia, Keech and coworkers ${ }^{37}$ found that the combination of fenofibrate and statin therapy may help reduce the risk MACE in diabetic CABG patients with severely elevated triglyceride levels $(>500 \mathrm{mg} / \mathrm{dL}$ ).

\section{Beta-Blockers}

Beta-blocker therapy is the treatment of choice for rate control and for decreasing the risk of atrial fibrillation in post-CABG patients, and is a quality metric for cardiac surgery in the STS database. ${ }^{38}$ Long-term beta-blocker therapy following CABG has been shown to reduce mortality and congestive heart failure (CHF) in patients with or without a history of previous MI or $\mathrm{CHF}^{39,40} \mathrm{~A}$ recent comprehensive review by Joseph and colleagues ${ }^{41}$ summarized the evidence supporting the use of beta-blockers in patients with congestive heart failure and preserved and reduced ejection fraction following ACS and stable coronary artery disease. Although most of their recommendations are derived from patients undergoing medical therapy and not surgical revascularization, they also serve to define those CABG patients who stand to benefit the most from beta-blockers in the perioperative period. They recommend using beta-blockers in patients with $\mathrm{CHF}$ and an ejection fraction $<40 \%$, in patients with hypertension or atrial fibrillation, and following an ACS, for which beta-blockers should be continued for up to 3 years. ${ }^{41}$

The current recommendations for the use of betablockers in $\mathrm{CABG}$ patients are as follows:

- All CABG patients without contraindications should receive beta-blockers for at least 24 hours before $\mathrm{CABG}$, to reduce the risk of postoperative atrial fibrillation; class I, LOE A. ${ }^{14,24}$

- CABG patients with a history of MI with or without reduced ejection fraction should receive a beta-blocker, unless contraindicated; class I, LOE A. ${ }^{14}$

- CABG patients with left ventricular dysfunction should receive beta-blocker therapy unless contraindicated; class I, LOE B. ${ }^{14}$

- Beta-blockers should be prescribed to all CABG patients without contraindications postoperatively and at the time of discharge; class I, LOE C. ${ }^{14,24}$

\section{Glycemic Control}

Hyperglycemia (serum blood glucose $>180 \mathrm{mg} / \mathrm{dL}$ ) that persists before, during, and after CABG is an independent predictor of operative mortality and morbidity, including infection, stroke, MI, and low cardiac output syndrome. ${ }^{42,43}$ Continuous insulin infusions designed to maintain serum 
glucose level $<180 \mathrm{mg} / \mathrm{dL}$ during the perioperative period after CABG surgery decrease mortality, intensive care unit (ICU) and hospital length of stay, the need for inotropic support, and the risk of infections and atrial fibrillation; improve long-term survival; and decrease the risk of recurrent angina. ${ }^{44-46}$ Because the diagnosis of diabetes mellitus is unknown before surgery in many patients, all CABG patients should have Hgb A1c measured before surgery, along with a fasting blood glucose level. Glycemic control is best instituted in the perioperative period with continuous insulin infusions and monitored throughout hospitalization by an in-hospital team composed of intensivists, endocrinologists, pharmacists, and dieticians in conjunction with the nursing and cardiac surgical services. Before discharge, all diabetic patients receiving insulin or noninsulin oral antiglycemic agents should receive education on glucose monitoring, nutrition, and lifestyle changes as well as follow-up visits with an endocrinologist.

The current guidelines for glycemic control in CABG patients are as follows:

- All patients undergoing CABG should have fasting glucose and Hgb Alc measured before surgery; class I, LOE C. ${ }^{47}$

- Continuous intravenous insulin infusion is the method of choice to achieve and maintain glycemic control (120$180 \mathrm{mg} / \mathrm{dL}$ ) in the perioperative period, class I, LOE A. ${ }^{47}$

- All oral diabetic medication should be discontinued 24 hours before surgery, especially sulfonylureas and glinides, to avoid hypoglycemia in the absence of food. Outpatients on insulin therapy should take their basal insulin dose on the morning of surgery but hold their nutritional insulin (LISPRO). NPH insulin should be reduced by one-half to one-third before surgery; class I, LOE B. ${ }^{47}$

- For preoperative patients with persistently elevated glucose values $>180 \mathrm{mg} / \mathrm{dL}$, an insulin drip should be initiated at least 12 hours before surgery; class $1, \mathrm{LOE}$ C. $^{47}$

- In the ICU, patients with persistently elevated serum glucose levels $>180 \mathrm{mg} / \mathrm{dL}$ should receive a continuous insulin infusion to keep serum glucose between 120 and $180 \mathrm{mg} / \mathrm{dL}$; class I, LOE A. ${ }^{47}$

- Patients who require $>3$ days of ICU care due to ventilatory, inotropic, or mechanical support, renal replacement therapy, or the need for antiarrhythmic agents should have a serum glucose level $<150 \mathrm{mg} / \mathrm{dL}$; class I, LOE B. ${ }^{46,47}$

- Following discharge from the ICU, patients receiving intravenous insulin infusions should be transitioned to a subcutaneous insulin dosing schedule. The target glucose goal should be $<110 \mathrm{mg} / \mathrm{dL}$ preprandial and $<180 \mathrm{mg} / \mathrm{dL}$ postprandial; class I, LOE A. ${ }^{47}$

- Patients with type 2 diabetes may be started on their oral medication once they have reached their targeted glucose goals and are tolerating a regular diet. Metformin should not be restarted until stable renal function has been achieved; class I, LOE C. ${ }^{47}$

- All attempts should be made to achieve a Hbg A1c $<7 \%$ in patients following CABG surgery to reduce both microvascular and macrovascular complications; class IIA; LOE B. ${ }^{14,47}$

\section{Smoking Cessation}

Smoking cessation is one of the most important risk modification goals for CABG patients. Patients who continue to smoke following CABG have a $68 \%$ greater risk for all-cause mortality and a $75 \%$ greater risk of cardiac death. In contrast, patients who stop smoking following CABG have a $41 \%$ reduction in the need for a repeat revascularization procedure. ${ }^{48}$ The postoperative period is the most effective time to institute smoking cessation strategies, which include behavioral counseling, nicotine replacement therapy, and medication with bupropion and varenicline. Nicotine replacement therapy is safe for patients with stable coronary artery disease but has been associated with increased mortality in patients with ACS. ${ }^{49}$ Bupropion is safe and effective for smoking cessation in all patients, including those following an MI. ${ }^{50}$ Although varenicline is also effective for smoking cessation, it has been associated with a nonsignificant increase in the incidence of nonfatal MIs and the need for coronary revascularization and should be used with caution in post-CABG patients. ${ }^{51}$ To further assist clinicians with smoking cessation, the American College of Cardiology recently released the "Expert Consensus Decision Pathway on Tobacco Cessation Treatment," ${ }^{, 2}$ which includes prescriptions for pharmacologic smoking cessation aids and evidence-based behavioral support groups. The current guidelines for smoking cessation in the CABG patient are as follows:

- Counseling should be offered to all patients who smoke during and after hospitalization for CABG to improve both short and long-term outcomes after surgery; class I, LOE A. $^{14}$

- It is reasonable to offer nicotine replacement therapy with bupropion and varenicline as adjuncts to smoking cessation counseling for stable CABG patients after hospital discharge; class I; LOE B. ${ }^{14}$

\section{Cardiac Rehabilitation}

Cardiac rehabilitation (CR) programs following CABG surgery play an important role in educating patients about secondary prevention and facilitate lifestyle and behavior modification to minimize MACE. Physician advocacy is the key factor in determining whether a patient will enroll in a CR program. ${ }^{53}$ Participation in an outpatient 
hospital-based CR program promotes adherence to secondary prevention therapies that were initiated during the post-CABG hospital stay.

The current guidelines for $\mathrm{CR}$ following $\mathrm{CABG}$ are as follows

- All CABG patients should be referred to a cardiac rehabilitation program during their postoperative hospital stay; class I; LOE A. ${ }^{14}$

\section{Mental Health, Emotional, and Psychosocial Therapy}

Preoperative depression and anxiety contribute not only to increased operative mortality and ICU and hospital length of stay, but also to decreased long-term survival and increased hospital readmissions. ${ }^{54,55}$ Every effort should be made to identify and treat these patients before CABG and even delay surgery in stable patients, given that preoperative therapy has resulted in decreased morbidity, mortality, and need for analgesic medication. ${ }^{56}$

Postoperative depression and delirium also have been associated with increased postoperative mortality, decreased long-term survival, and increased rates of recurrent angina, $\mathrm{MI}$, rehospitalization for $\mathrm{CHF}$, and the need for repeat revascularization procedures. ${ }^{57-59}$ This is most likely due to poor compliance with GDMT and secondary prevention therapies. Symptoms of anxiety and postoperative depression may be indicative of dementia and should not simply be dismissed as postoperative anxiety. Interventions to treat post-CABG depression, such as the use of antidepressant medication and psychotherapy, should be initiated immediately in the hospital and have been associated with decreased mortality, reduced analgesic use, and shorter hospital length of stay. ${ }^{60,61}$ These interventions allow patients to better participate in postoperative care programs and they are more likely to be compliant with secondary prevention therapies. ${ }^{62}$ The current guidelines for mental health, emotional, and psychosocial therapies in the $\mathrm{CABG}$ patient are as follows:

- Following CABG surgery, all patients should be screened for depression; class IIA, LOE B. ${ }^{14}$

\section{LEVEL OF COMPLIANCE WITH GDMT AND SECONDARY PREVENTION IN CABG PATIENTS}

Despite the proven benefits of GDMT in prolonging survival and decreasing MACE and the need for rerevascularization procedures, compliance with secondary prevention therapies in $\mathrm{CABG}$ patients remains poor. CABG patients are less likely the patients undergoing a PCI to fill secondary prevention medications on discharge. Pinho-Gomes and colleagues ${ }^{3}$ found on $50 \%$ adherence to GDMT in CABG patients at 5 years after surgery. In 2389 CABG patients, Filion and colleagues ${ }^{63}$ observed that only $23 \%$ of patients with a history of hypertension received an ACE inhibitor on discharge, and only 64\% received a statin. Looi and colleagues ${ }^{64}$ found that after 3 years, only $43 \%$ of CABG patients were on ACE inhibitors and only $72 \%$ received a statin. According to Belcher and coworkers, ${ }^{65}$ at 1 year after CABG, only $70 \%$ of patients were on receiving ASA, $18 \%$ were receiving no antiplatelet agents, $24 \%$ were receiving an ACE inhibitor, $17 \%$ were receiving a beta-blocker, and only $28 \%$ were receiving a statin. There was no reduction in the incidence of active smokers, and there was a significant rise in systolic blood pressure $(135 \pm 20 \mathrm{~mm} \mathrm{Hg}$ vs $148 \mathrm{~mm} \mathrm{Hg} \pm 25 \mathrm{~mm}$ $\mathrm{Hg} ; P<.001)$. The detrimental effects of not taking antiplatelet agents, beta-blockers, ACE inhibitors, and statins at discharge and 1 year post-CABG were reported by Goyal and colleagues in 2970 patients. ${ }^{66}$ Patients taking one-half or fewer of these medications had a significantly higher incidence of death or MI at 2 years after CABG $(P<.013)$. Pinho-Gomes and colleagues ${ }^{3}$ found that CABG patients who were noncompliant with GDMT were more likely to have decreased long-term survival and freedom from MACE. Equally important, the superior outcomes achieved with CABG over PCI early after revascularization became less apparent as compliance with GDMT decreased in CABG patients compared with PCI patients. The negative impact resulting from nonadherence to GDMT was also observed by Kurlansky and colleagues ${ }^{4}$ in 2352 patients undergoing CABG or PCI who were enrolled in the Coronary Artery Revascularization Evaluation (CARE) registry. Outcomes of CABG were superior to those of PCI in patients who were nonadherent to GDMT; however, there was no difference in outcomes between CABG and PCI in patients who were adherent with GDMT. Regardless of the revascularization strategy used, MACE-free survival was significantly improved in patients who were adherent with GDMT.

\section{FACTORS RESPONSIBLE FOR POOR COMPLIANCE WITH GDMT IN CABG PATIENTS}

In view of the overwhelming evidence showing that noncompliance with GDMT significantly negates the beneficial effects of CABG, why is compliance with secondary prevention therapies so low? There are several possible explanations:

- Patients are frequently led to believe that CABG is the most definitive therapy for their coronary artery disease, and thus long-term treatment with medications might not be necessary.

- There is a misconception among cardiologists and some surgeons that performing CABG with complete total arterial revascularization will eliminate the need for further GDMT. This is reinforced by the fact that CABG provides a survival benefit over PCI by protecting 
patients against a new MI. ${ }^{67}$ MI remains the leading cause of death following PCI. ${ }^{68}$ The etiologies of recurrent MACE differ following CABG and PCI. Recurrent angina is a more common recurrent ischemic event in CABG patients compared with MI or ACS in PCI patients, and thus cardiologists are more likely to aggressively pursue adherence to GDMT in their PCI patients to avoid a potentially fatal ACS event.

- CABG patients may not always be followed long-term by a cardiologist or an internist with a special interest in cardiovascular medicine. Unfortunately, primary care physicians and nurse practitioners are not always aware of the latest guidelines for secondary prevention following CABG and are more likely to decrease or discontinue ASA, statins, beta-blockers, and ACE inhibitors once target goals have been reached.

- Patients may find that medications for secondary prevention are too costly and are not always covered by thirdparty payers.

\section{DEVELOPING INTERVENTIONS TO ENSURE COMPLIANCE WITH GDMT IN CABG PATIENTS}

What role can surgeons play to enhance compliance with GDMT in their CABG patients? Because patients in whom GDMT is instituted at the time of hospital discharge are more likely to achieve long-term compliance with GDMT, ${ }^{69,70}$ every effort should be made to initiate a "get with the guidelines" program to target goals that can be maintained in outpatient programs and at home. ${ }^{71,72} \mathrm{~Pa}-$ tients who are ready for discharge should receive a discharge packet that includes a list of all GDMT medications and programs. This information should be reviewed with the patient by a member of the cardiac surgery team, either an NP or a PA, but not a floor nurse, who is more likely to concentrate on issues related to the immediate postoperative period, such as wound care and sternal precautions, instead of long-term GDMT and secondary prevention therapy.

Another mechanism to improve compliance with discharge medical therapy is the use of "quality indicators," such as the use of discharge prescriptions for ASA, beta-blockers, statins and ACE inhibitors to assess adherence with discharge medications, similar to the 3-star rating system adopted by the STS. In a study of STS participating hospitals, CABG patients were randomized into a control or intervention group. ${ }^{73}$ The intervention group received "feedback reports" on the compliance with discharge prescriptions for ASA, beta-blockers, statins, and ACE inhibitors every 6 months, along with patient education materials that stressed the importance of secondary prevention medications and lifestyle modifications. Compliance with these 4 medications was significantly increased over the 24-month period following CABG in the intervention group. It has been estimated that the simultaneous use of an ACE inhibitor, ASA, a beta-blocker, and a statin simultaneously in patients with cardiovascular disease can decrease ischemic events by at least $14 \% .^{74}$

Another approach to improving compliance with GDMT is for surgeons to encourage and institute enrollment in either an inpatient or an outpatient rehabilitation program. ${ }^{75}$ This should be advocated for all patients irrespective of their age and social or educational background. The early postoperative period, during which time the trauma of the surgery is still fresh in the patient's mind, is the best time to stress the importance of secondary prevention therapies. Rehabilitation programs provide an environment in which GDMT and lifestyle changes can be best promoted to achieve optimal patient compliance. Because the cost of medications can be a significant deterrent to compliance with GDMT, surgeons, cardiologists, NPs, and PAs should be cognizant of methods to decrease the cost of these drugs. These include using lower-cost insurance-preferred formularies, enrollment in medication assistance programs, and prescribing of lower-cost but high-quality alternative drugs.

Although these inpatient and postdischarge rehabilitation programs can achieve initial success, maintaining compliance with long-term GDMT remains a problem, especially for patients who are no longer being followed by a cardiologist or an internist with an interest in cardiovascular diseases. It is often difficult for surgeons to follow their CABG patients after their initial postoperative visit, because these patients are normally seen by their local physicians who assume their medical care and are reimbursed for these visits. Another option could be to institute a "cardiac revascularization clinic" at the hospital where the CABG or PCI was performed to provide long-term follow-up for both procedures. The "heart team" approach is being advocated for determining the best approach for coronary revascularization, and it makes sense to follow all these patients in a single clinic. This would be similar to what is now being performed at a heart valve clinic, a transplant clinic or an oncology clinic for lung cancer. This would ensure that all CABG patients are seen by cardiovascular specialists who are knowledgeable with the most recent guidelines for secondary prevention following coronary revascularization. Patients would have their blood pressure, lipid levels, and $\mathrm{Hgb} \mathrm{A} 1 \mathrm{c}$ checked on a regular basis. Not only would adherence to GDMT be assessed, but also the needed changes in medication and dosages could be made to ensure achievement of the appropriate targeted values. This clinic would also serve as a "revascularization registry" similar to that for TAVR, so that long-term MACE, need for re-revascularization, and mortality could be recorded. Patients being followed by their local cardiovascular physicians and those that live at longer distances could have their laboratory values and outcome data sent to the registry, so that all CABG patients would have 
some form of follow-up. Support for such a revascularization clinic and registry from societies such as the AATS, STS, ACC, and AHA would facilitate reimbursement from CMS and third-party payers, given that compliance with GDMT decreases long-term MACE and would result in a significant health care cost savings for CABG patients.

\section{CONCLUSIONS}

Maintaining GDMT following CABG is vital to minimize MACE, prolong survival, and improve quality of life. Interventions should be instituted by surgeons in the postoperative period, while patients are still hospitalized, to ensure maximal patient compliance with GDMT and secondary prevention therapies. Proper follow-up after discharge by physicians familiar with the latest secondary prevention guidelines is essential to ensure that CABG patients continue to receive GDMT, so that the superior benefits derived from surgical revascularization continue for years after surgery.

\section{Conflict of Interest Statement}

Author has nothing to disclose with regard to commercial support.

\section{References}

1. Hiratzka LF, Eagle KA, Liang L, Fonarow GC, LaBresh KA, Peterson ED. Atherosclerosis secondary prevention performance measures after coronary bypass graft surgery compared with percutaneous catheter intervention and nonintervention patients in the Get with the guidelines database. Circulation. 2007;116(11 Suppl):I207-12.

2. Hlatky MA, Solomon MD, Shilane D, Leong TK, Brindis R, Go AS. Use of medications for secondary prevention after coronary bypass surgery compared with percutaneous coronary intervention. J Am Coll Cardiol. 2013;61:295-301.

3. Pinho-Gomes AC, Azevedo L, Ahn JM, Park SJ, Hamza TH, Farkouh ME, et al. Compliance with guideline-directed medical therapy in contemporary coronary revascularization trials. J Am Coll Cardiol. 2018;71:591-602.

4. Kurlansky P, Herbert M, Prince S, Mack M. Coronary artery bypass graft versus percutaneous coronary intervention: meds matter: impact of adherence to medical therapy on comparative outcomes. Circulation. 2016;134:1238-46.

5. Goldman S, Copeland J, Moritz T, Henderson W, Zadina K, Ovitt T, et al. Saphenous vein graft patency 1 year after coronary artery bypass surgery and effects of antiplatelet therapy. Results of a veterans administration cooperation study. Circulation. 1989;80:1190-7.

6. Mangano DT; Multicenter Study of Perioperative Ischemia Research Group. Aspirin and mortality from coronary bypass surgery. $N$ Engl J Med. 2002;347: 1309-17.

7. Johnson WD, Kayser KL, Hartz AJ, Saedi SF. Aspirin use and survival after coronary bypass surgery. Am Heart J. 1992;123:603-8.

8. Windecker S, Kolb P, Alfonso F, Collet JP, Cremer J, Falk V, et al. 2014 ECS/ EACTS guidelines on myocardial revascularization: the task force on myocardial revascularization of the European Society of Cardiology (ESC) and the European Association for Cardio-Thoracic Surgery (EACTS) developed with the special contribution of the European Association of Percutaneous Cardiovascular Interventions (EAPCI). Eur Heart J. 2014;35:2541-619.

9. Bybee KA, Powell BD, Valeti U, Rosales AG, Kopecky SL, Mullany C, et al. Preoperative aspirin therapy is associated with improved postoperative outcomes in patients undergoing coronary artery bypass grafting. Circulation. 2005;112(9 Suppl):286-92.

10. Wang Z, Gao F, Men J, Ren J, Modi P, Wei M. Aspirin resistance in off-pump coronary artery bypass grafting. Eur J Cardiothorac Surg. 2012;41:108-12.

11. Mannacio VA, Di Tommaso L, Antignan A, De Amicis U, Vosa C. Aspirin plus clopidogrel for optimal platelet inhibition following off-pump coronary artery bypass surgery: results from the CRYSSA (prevention of Coronary arteRY
bypaSS occlusion After off-pump procedures) randomised study. Heart. 2012 98:1710-5.

12. Deo SV, Dunlay SM, Shah IK, Altarabsheh SE, Erwin PJ, Bollson BA, et al. Dual anti-platelet therapy after coronary artery bypass grafting: is there any benefit? A systemic review and meta-analysis. J Card Surg. 2013;28:109-16.

13. Stein PD, Dalen JE, Goldman S, Schwartz L, Theroux P, Turpie AG. Antithrombotic therapy in patients with saphenous vein and internal mammary artery bypass grafts. Chest. 1995;108(4 Suppl):424S-30S.

14. Kulik A, Ruel M, Jneid T, Fergusson TB, Hiratzka JF, Ikonomidis JS, et al. Secondary prevention after coronary artery bypass graft surgery: a scientific statement from the American Heart Association. Circulation. 2015;131:927-64.

15. Herlitz J. Mortality, risk indicators, mode and place of death and symptoms of angina pectoris in the five years after coronary artery bypass grafting in patients with and without a history of hypertension. Blood Press. 1999;8:200-6.

16. Brown NJ, Agirbasli MA, William GH, Litchfield WR, Vaughan DE. Effect of activation and inhibition of the rennin-angiotensin system on plasma PAI-1. Hypertension. 1998;32:965-71.

17. Lazar HL. All coronary artery bypass graft surgery patients will benefit from angiotensin-converting enzyme inhibitors. Circulation. 2008;117:6-8.

18. Oosterga M, Voors AA, Pinto YM, Buikema H, Grandjean JG, Kingma JH, et al. Effects of quinapril on clinical outcome after coronary artery bypass grafting (The QUO VADIS study). Quinipril on vascular ACE and determinants of ischemia. Am J Cardiol. 2011;87:542-6.

19. Kjøller-Hansen L, Steffensen R, Grande P. The angiotensin-converting enzyme in hibition post revascularization study (APRES). J Am Coll Card. 2000;35:881-8.

20. Shi P, Li Z, Young N, Ji F, Wang Y, Moore P, et al. The effects of preoperative renin-angiotensin system inhibitors on outcomes in patients undergoing cardiac surgery. J Cardiothorac Vasc Anesth. 2013;27:703-9.

21. Kalavrouziotis D, Buth KJ, Cox JL, Baskett RJ. Should all patients be treated with an angiotensin-converting enzyme inhibitor after coronary artery bypass surgery? The impact of angiotensin-converting enzyme inhibitors, statins, and $\beta$-blockers after coronary artery bypass graft surgery. Am Heart J. 2011;162: 836-43.

22. Deakin CD, Dalrymple-Hay MJ, Jones P, Monro JL. Effects of angiotensin-converting enzyme inhibition on systemic vascular resistance and vasoconstrictor requirements during hypothermic cardiopulmonary bypass. Eur J Cardiothorac Surg. 1998;13:546-50.

23. Pigott DW, Nagle C, Allman K, Westaby S, Evans RD. Effect of omitting regular ACE inhibitor medication before cardiac surgery on haemodynamic variables and vasoactive drug requirements. Br J Anaesth. 1999;83:715-20.

24. Hillis LD, Smith PK, Anderson JL, Bittl JA, Bridges CR, Byrne JG, et al. 2011 ACCF/AHA guideline for coronary artery bypass graft surgery: executive summary: a report of the American College of Cardiology Foundation/American Heart Association task force on practice guidelines. J Thorac Cardiovasc Surg. 2012;143:4-34.

25. Lazar HL. Role of statin therapy in the coronary bypass patient. Ann Thorac Surg 2004;78:730-40

26. Dotani MI, Elnicki DM, Jain AC, Gibson CM. Effect of preoperative statin therapy and cardiac outcomes after coronary artery bypass grafting. Am J Cardiol. 2000;86:1128-1130, A6.

27. Kulik A, Brookhart MA, Levin R, Ruel M, Solomon DH, Choudhry NK. Impact of statin use on outcomes after coronary artery bypass graft surgery. Circulation 2008; 118:1785-92.

28. Post Coronary Artery Bypass Trial Investigators. The effect of aggressive lowering of low density lipoprotein cholesterol levels and low dose anticoagulation on obstructive changes in saphenous-vein coronary-artery bypass grafts. $N$ Engl J Med. 1997;336:153-62.

29. LaRosa JC, Grundy SM, Waters DD, Shear C, Barter P, Fruchart JC, et al. Intensive lipid lowering with atorvastatin in patients with stable coronary artery disease. $N$ Engl J Med. 2005;352:1425-35.

30. Foody JM, Ferdinand FD, Pearce GL, Lytle BW, Cosgrove DM, Sprecher DL. HDL cholesterol levels predict survival in men after coronary artery bypass graft surgery: 20-year experience from the Cleveland Clinic Foundation. Circulation. 2000;102(19 Suppl 3):III90-4.

31. Frick MH, Syvänne M, Nieminen MS, Kauma H, Majahalme S, Virtanen V, et al. Prevention of the angiographic progression of coronary and vein-graft atherosclerosis by gemfibrozil after coronary bypass surgery in men with low levels of HDL cholesterol. lopid coronary angiography trial (LOCAT) study group. Circulation. 1997:96:2137-43.

32. Jones PH, Davidson MH. Reporting rate of rhabdomyolysis with fenofibrate statin versus gemfibrozil + any statin. Am J Cardiol. 2005;95:120-2. 
33. Mennander A, Angervuori T, Huhtala H, Karhunen P, Tarkka M, Kuukasjärvi P. Positive family history of coronary atherosclerosis and serum triglycerides may predict repeated coronary artery bypass surgery. Scand Cardiovasc J. 2005;39:225-8.

34. Sabik JF III, Blackstone EH, Gillinov AM, Smedira NG, Lytle BW. Occurrence and risk factors for reintervention after coronary artery bypass grafting. Circulation. 2006;114(1 Suppl):I454-60.

35. Sprecher DL, Pearce GL, Cosgrove DM, Lytle BW, Loop FD, Pashkow FJ. Relation of serum triglyceride levels to survival after coronary artery bypass grafting. Am J Cardiol. 2000;86:285-8.

36. Allard C, Ruscito O, Goulet C. The influence of serum triglycerides on the fate of aortocoronary vein grafts. Can Med Assoc J. 1972;107:213-6.

37. Keech A, Simes RJ, Banter P, Best J, Scott R, Taskinen MR, et al. Effects of longterm fenofibrate therapy on cardiovascular events in 9795 patients with type 2 diabetes mellitus (the FIELD study): randomized controlled trial. Lancet. 2005;366:1849-61.

38. O'Brien SM, Shahian DM, DeLong ER, Normand SL, Edwards FH, Ferrans VA, et al. Quality measurement in adult cardiac surgery: part 2-statistical considerations in composite measure scoring and provider rating. Ann Thorac Surg. 2007;83(4 Suppl):S13-26.

39. Chan AY, McAlister FA, Norris CM, Johnstone D, Bakal JA, Ross DB. Effect of beta-blocker use on outcomes after discharge in patients who underwent cardiac surgery. J Thorac Cardiovasc Surg. 2010;140:182-7.

40. Zhang H, Yuan X, Zhang H, Chen S, Zhao Y, Hua K, et al. Efficacy of long-term $\beta$-blocker therapy for secondary prevention of long-term outcomes after coronary artery bypass grafting surgery. Circulation. 2015;131:2194-201.

41. Joseph P, Swedberg K, Leong DP, Yusef S. The evolution of $\beta$-blockers in coronary artery disease and heart failure (Part 1/5). J Am Coll Cardiol. 2019;74:672-82.

42. Carson JL, Scholz PM, Chen AY, Peterson ED, Gold J, Schneider SH. Diabetes mellitus increases short-term mortality and morbidity in patients undergoing coronary artery bypass graft surgery. J Am Coll Cardiol. 2002;40:418-23.

43. Fish LH, Weaver TW, Moore AL, Steel LG. Value of postoperative blood glucose in predicting complications and length of stay after coronary artery bypass grafting. Am J Cardiol. 2003;92:74-6.

44. Furnary AP, Gao G, Grunkemeier GL, Wu Y, Zerr KJ, Bookin SO, et al. Continuous insulin infusion reduces mortality in patients with diabetes undergoing coronary artery bypass grafting. J Thorac Cardiovasc Surg. 2003;125:1007-21.

45. Lazar HL, Chipkin SR, Fitzgerald CA, Bao Y, Cabral H, Apstein CS. Tight glycemic control in diabetic coronary artery bypass graft patients improves perioperative outcomes and decreases recurrent ischemic events. Circulation. 2004; 109:1497-502.

46. van den Berghe G, Wouters P, Weekers F, Verwaest C, Bruyninckx F, Schetz M, et al. Intensive insulin therapy in critically ill patients. N Eng J Med. 2001;345: 1359-67.

47. Lazar HL, McDonnell M, Chipkin SR, Furnary AP, Engelman RM, Sadhu AR, et al. The Society of Thoracic Surgeons practice guidelines series: blood glucose management during adult cardiac surgery. Ann Thorac Surg. 2009;87:663-9.

48. van Domburg RT, Meeter K, van Berkel DF, Veldkamp RF, van Herwerden LA, Bogers AJ. Smoking cessation reduces mortality after coronary artery bypass surgery: a 20-year follow-up study. J Am Coll Cardiol. 2000;36:878-83.

49. Paciullo CA, Short MR, Steinke DT, Jennings HR. Impact of nicotine replacement therapy on postoperative mortality following coronary artery bypass graft surgery. Ann Pharmacother. 2009;43:1197-202.

50. Eisenberg MJ, Grandi SM, Gervais A, O’Loughlin J, Paradis G, Rinfret S, et al. Bupropion for smoking cessation in patients hospitalized with acute myocardial infarction: a randomized, placebo-controlled trial. J Am Coll Cardiol. 2013;61: 524-32.

51. Rigotti NA, Pipe AL, Benowitz NL, Arteaga C, Garza D, Tonstad S. Efficacy and safety of varenicline for smoking cessation in patients with cardiovascular disease: a randomized trial. Circulation. 2010;121:221-9.

52. Barua RS, Rigotti NA, Benowitz NL, Cummings KM, Jazayeri MA, Morris PB, et al. 2018 ACC expert consensus decision pathway on tobacco cessation treatment: a report of the American College of Cardiology task force on clinical expert consensus documents. J Am Coll Cardiol. 2018;72:3332-65.

53. Grace SL, Gravely-Witte S, Brual J, Suskin N, Higginson L, Alter D, et al. Contribution of patient and physician factors to cardiac rehabilitation referral: a prospective multilevel study. Nat Clin Pract Cardiovasc Med. 2008;5:653-62.

54. Dao TK, Youssef NA, Armsworth M, Wear E, Papathopoulos KN, Gopaldas R. Randomized controlled trial of brief cognitive behavioral intervention for depression and anxiety symptoms preoperatively in patients undergoing coronary artery bypass graft surgery. J Thorac Cardiovasc Surg. 2011;142:e109-15.

55. Flaherty LB, Wood T, Cheng A, Khan AR. Pre-existing psychological depression confers increased risk of adverse cardiovascular outcomes following cardiac surgery: a systemic review and meta-analysis. J Thorac Cardiovasc Surg. 2017;154: 1578-15786.e1.

56. Chacron S, Vandel P, Durst C, Laluc F, Kaili D, Chacron M, et al. Antidepressant therapy in patients undergoing coronary artery bypass grafting: the MOTIVCABG trial. Ann Thorac Surg. 2013;95:1609-18.

57. Blumenthal JA, Lett HS, Babyak MA, White W, Smith PK, Mark DB, et al. Depression as a risk factor for mortality after coronary artery bypass surgery. Lancet. 2003;362:604-9.

58. Connerney I, Shapiro PA, McLaughlin JS, Bagiella E, Sloan RP. Relation between depression after coronary artery bypass surgery and 12-month outcome: a prospective study. Lancet. 2001;358:1766-71.

59. Koster S, Hensens AG, Schuurmans J, van der Palen J. Consequences of delirium after cardiac operations. Ann Thorac Surg. 2012;93:705-11.

60. Mumford E, Schlesinger HJ, Glass GV. The effects of psychological intervention on recovery from surgery and heart attacks: an analysis of the literature. Am J Public Health. 1982;72:141-51.

61. Perski A, Osuchowski K, Andersson L, Sanden A, Feleke E, Anderson G. Intensive rehabilitation of emotionally distressed patients after coronary by-pass grafting. J Intern Med. 1999;246:253-63.

62. Trzcienlecka-Green A, Steptoe A. The effects of stress management and quality of life of patients following acute myocardial infarction or coronary bypass surgery. Eur Heart J. 1996;17:1663-70.

63. Filion KB, Pilote L, Rahme E, Eisenberg MJ. Use of perioperative cardiac medical therapy among patients undergoing coronary artery bypass graft surgery. $J$ Card Surg. 2008;23:209-15.

64. Looi KL, Chow KL, Looi JL, Lee M, Halliday S, White H, et al. Under-use of secondary prevention medication in acute coronary syndrome patients treated with in-hospital coronary artery bypass graft surgery. $N$ Z Med J. 2011;124: $18-27$.

65. Belcher PR, Gaw A, Cooper M, Brown M, Wheatley DJ, Lindsay GM. Are we negating the benefits of CABG by forgetting secondary prevention? J Hum Hypertens. 2002;16:691-7.

66. Goyal A, Alexander JH, Hafley GE, Graham SH, Mehta RH, Mack MJ, et al Outcomes associated with the use of secondary prevention medications after coronary artery bypass graft surgery. Ann Thorac Surg. 2007;83: 993-1001.

67. Doenst T, Haverich A, Serruys P, Bonow RO, Kappetein P, Falk V, et al. PCI and $\mathrm{CABG}$ for treating stable coronary artery disease: JACC review topic of the week. J Am Coll Cardiol. 2019:73:964-76.

68. Milojevic M, Head SJ, Parasca CA, Serruys PW, Mohr FW, Morice MC, et al. Causes of death following PCI versus CABG in complex CAD: 5-year followup of SYNTAX. J Am Coll Cardiol. 2016;67:42-55.

69. Eisenberg MJ, Okrainec K, Lefkovits J, Goudreau E, Deligonul U, Mak KH, et al. Medical therapy in patients undergoing percutaneous coronary intervention: results from the ROSETTA registry. Can J Cardiol. 2003;19:1009-15.

70. Okrainec K, Pilote L, Platt R, Eisenberg MJ. Use of cardiovascular medical therapy among patients undergoing coronary artery bypass graft surgery: results from the ROSETTA-CABG registry. Can J Cardiol. 2006;22:841-7.

71. Fonarow GC, Gawlinski A, Moughrabi S, Tillisch JH. Improved treatment of cor onary heart disease by implementation of a cardiac hospitalization atheroscle rosis management program (CHAMP). Am J Cardiol. 2001;87:819-22.

72. Denton TA, Fonarow GC, LaBresh KA, Trento A. Secondary prevention after coronary bypass: the American Heart Association "Get with the Guidelines" program. Ann Thorac Surg. 2003;75:758-60.

73. Williams JB, Delong ER, Peterson ED, Dokholyan RS, Ou FS, Ferguson TB Jr. Secondary prevention after coronary artery bypass graft surgery: findings of a national randomized controlled trial and sustained society-led incorporation into practice. Circulation. 2011;123:39-45.

74. Yusef S. Two decades of progress in preventing vascular disease. Lancet. 2002; 360:2-3.

75. Griffo R, Ambrosetti M, Tramarin R, Fattirolli F, Temporelli PL, Vestri AR, et al. Effective secondary prevention through cardiac rehabilitation after coronary revascularization and predictors of poor adherence to lifestyle modification and medication. Results of the ICAROS survey. Int J Cardiol. 2013;167:1390-5. 